\title{
The richness behind the EFA-GMR contributions
}

\author{
Clementina Acedo
}

Published online: 19 June 2009

(C) UNESCO IBE 2009

The theme of this special issue takes us to the very heart of the Education for All (EFA) agenda, as it offers informed insights into the history of the EFA goals and progress towards their realization, both at the global level and in specific national contexts, as well as giving fresh perspectives on current debates related to the EFA agenda.

The articles published in this special issue on "Education for All by 2015: Progress and Challenges" are based on background papers commissioned for the 2008 EFA Global Monitoring Report (GMR), Education for All by 2015. Will we make it?, which offered a midway assessment of the progress towards reaching the EFA targets by 2015 . This special issue draws attention to timely lessons concerning the obstacles and successes encountered on the path to achieving the EFA goals.

In his Introduction entitled "Education for All: Achievements and Prospects", Aaron Benavot, the guest-editor of this issue, who served as a Senior Policy Analyst on the EFA Global Monitoring Report team at UNESCO in Paris, brings into sharper focus the main themes of this collection of papers. His article presents a comprehensive overview of progress toward EFA since Dakar, while also discussing clear priorities for both international stakeholders and national governments for the coming years.

This special issue presents an enlightening collection of articles that explores a diversity of complex topics relevant in overcoming exclusion in the EFA process, such as: aid effectiveness; gender bias; non-formal education; and participation in basic education. The first part of the issue, the Open File, tackles these themes at a more general, global level, while the second part analyses various challenges related to quality and equity encountered in specific regional and national contexts.

Contributors include: Batuhan Aydagül, Aaron Benavot, Rae Lesser Blumberg, Gabrielle Bonnet, Gabriel Buchmann, Rhona B. Caoli-Rodriguez, Amgaabazar Gerelmaa, Rangachar Govinda, Wim Hoppers, Marcelo Neri, Steve Packer, Abby Riddell, Joel D. Sherman, Gita Steiner-Khamsi and Eric Woods-distinguished scholars who bring their own analyses and assessments into the issues that confront the realization of the EFA goals by 2015 .

C. Acedo $(\square)$

IBE UNESCO, P.O. Box 199, 1211 Geneva 20, Switzerland

e-mail: c.acedo@ibe.unesco.org 
Steve Packer introduces the EFA-GMR as a means to track progress towards the accomplishment of the six EFA goals and to make governments and the international community accountable for commitments made at the Dakar meeting in 2000. The author looks back at the legacy of the seven GMRs published by UNESCO over the past six years, and looks ahead to the challenges and opportunities that will face the world during the next seven years. As 2015 draws closer, Packer argues, the GMRs will need to adjust their "mould of reporting that was perfectly sensible in the years immediately after Dakar" and their arguments by taking into account, among other things, wider sector strategies (e.g. more analysis of sector plans and programmes); greater attention to rates of progress over time regarding literacy and gender equality; and encouraging debate about the definitions of EFA goals.

Wim Hoppers analyses the important, but often unrecognized, role that non-formal education plays in the achievement of EFA, mainly by contributing to the improvement of access, quality and relevance of basic education. Based on data from various countries in the South, the article argues that, despite many problems faced by frameworks of nonformal education, they represent viable alternatives for accessing and completing basic education. In many contexts, non-formal education also contributes to skills development among increasingly diverse populations that are often vulnerable to marginalization and exclusion.

Wide gaps in EFA progress exist within particular regions and countries. Looking beyond national indicators related to the goals of universal primary education and improved education quality, Joel Sherman analyses disparities in participation in primary education before and after the Dakar Framework in sixty countries in Sub-Saharan Africa, the Arab States, Latin America and in the Asia and Pacific region. Using disaggregated institutional data, the author indicates startling inequalities and disparities among different demographic and social groups, as well as among geographical regions within countries.

As many countries remain "off-track" in achieving the EFA goals and the Millennium Development Goals (MDGs), new ways of delivering aid are being envisioned in order to make aid more effective. Abby Riddell analyses the development and impact of these new modalities, including sector-wide approaches and direct budget support, as perceived by senior staff in selected major development agencies. Mixed results bear out the effects that these new ways of delivering aid have had on the education sectors of developing countries. While increased aid for education has supported the expansion of school access, little progress has been observed in improving education quality and in developing institutional capacities. Riddell concludes that, in order to achieve a main EFA goal-quality education for all, much work remains to be done. This would also ensure, among other things, that "the implementation interface is not driven by donors wanting to show the impact of the new aid modalities themselves, rather than of quality EFA".

Rae Lesser Blumberg argues that gender bias in textbooks represents an invisible obstacle to achieving another EFA goal, namely gender equality in education. Case studies from China, India, Romania, Syria and the United States of America document this important issue, which is illustrative of taken-for-granted stereotypes about gender roles and the persistence of various types of bias against women more generally. As the design and development of new, bias-free textbooks would be an extremely expensive undertaking, Blumberg discusses alternative methods to combat gender bias in existing textbooks. Among them, she mentions: teachers and students identifying biases and confronting them (e.g. by suggesting ways to remove them); training teachers to identify and counter gender bias; and an anti-gender bias manual, which could be crafted using the findings of significant research on this matter. 
Gabrielle Bonnet investigates the relationship between teachers' qualifications and training and teachers' actual knowledge and behaviour. Focusing on Sub-Saharan Africa she finds out that there is a weak association between teachers' academic qualifications and professional development on the one hand, and teachers' test scores and behaviour on the other. This tenuous link, the author argues, may help explain the weak relationship between teachers' qualifications and training and subsequent student achievement. While measurable teacher attributes, such as education, training and experience, apparently account for little variation in student progress in Africa, there are other factors related to a "class effect" (the impact on a student of being in one class rather than another) that explain almost one-third of a student's performance progress during the course of a year.

The second section of this special issue, entitled "Case studies of progress and challenges in quality and equity", comprises succinct analyses of the ways in which the realization of the EFA goals is affected by social, cultural, economic and political forces in countries as diverse as India, Mongolia, the Philippines, Tanzania and Turkey. These cases display an extraordinarily sensitive grasp of the complexity of national and local contexts in distorting, hindering or advancing the accomplishment of the EFA target goals.

Turkey deserves particular attention since, according to Batuhan Aydagül, this country remains far from realizing any of the six EFA goals. Despite a multiplicity of policy initiatives aimed at improving the quality of Turkish education, there are still serious educational disparities related to region, gender and socio-economic status, and to inadequate public spending per primary-level student. Among the factors that can trigger progress towards achieving the EFA goals, the author underscores the need to adopt strategy-oriented sector policies; to build political and economic support for education reform; to increase capacity and emphasis on evaluation and accountability of educational policy-making; and to embark on a new national thrust towards improving education quality.

The Philippines have been experiencing a decline in primary and secondary education performance indicators and a steadily widening gap between boys' and girls' achievements. Because of this, in Rhona Caoli-Rodriguez' words, the country will be "hardpressed to achieve the EFA goals by 2015". The author urges the introduction of efficient measures that would counterbalance the prevalence of insufficient political will, discontinuity in educational leadership and weak implementation of educational projects and innovations. She specifically mentions the need for a stronger emphasis on the long-term benefits of basic education; updated education data to assist in monitoring and evaluation and to keep all stakeholders informed; and the development of a more aggressive population-control and family-planning programme.

Eric Woods identifies positive developments in Tanzania, including a strong policy and planning environment favourable to the realization of the MDGs and the universalization of primary education. He emphasizes the lack of gender disparities in primary enrolment and the poor attention given to children living with disabilities. Nevertheless, increased enrolment rates and outdated curricula and pedagogy have had a negative effect on school quality, thus supporting the perception that increasing access decreases education quality. Woods concludes that a major overhaul of teacher training, support and the provision of educational resources is needed in order for Tanzania to achieve the EFA goals by 2015 .

Brazil represents an interesting case since the national government launched an ambitious development plan addressing the EFA goals, complemented by the active participation of the Brazilian civil society. Marcelo Neri and Gabriel Buchmann point to unprecedented progress regarding the universalization of primary education; falling rates of illiteracy; and greater gender equity. However, the authors observe that while 
quantitative indicators improved over the period, most qualitative indicators worsened. For instance, student proficiency indicators have deteriorated from what was already a low level. Yet, it is in the involvement of civil society, coupled with the Brazilian government's commitment to the EFA goals, that the authors optimistically identify a unique opportunity to scale up and co-ordinate efforts to achieve quality education for all.

Gita Steiner-Khamsi and Amgaabazar Gerelmaa examine the inverse gender gap in the Mongolian education system, namely the fact that boys from herder families in remote rural areas are at the greatest risk of drop-out or non-enrolment. The authors analyse in depth the links between gender, household income and school location (urban, semi-urban, rural) on educational access, and conclude that the EFA goals and the MDGs are insufficiently tailored to education systems that include nomadic populations, such as the children of herder families in Mongolia.

Rangachar Govinda reviews two decades of EFA progress in India in the context of a rapidly growing population, which has historically outpaced the capacity of schools to enrol and educate children. However, India seems to be on the right track. The optimism underlying the realization of the universal elementary education goal is based on evidence of a rapidly growing economy, falling birth rates, translated into a reduced demand for school places, and an unprecedented increase in people's participation in education (both seeking and supporting educational activities). Increases in literacy rates and the move towards gender parity are equally impressive and give realistic hope that India can meet the EFA goals by 2015 . Yet, challenges concerning regional imbalances and social inequity remain. In particular, the inclusion of the most marginalized among the traditionally disadvantaged social groups and minority communities remains an acute, unsolved and evaded problem.

This special issue of Prospects is certainly a call to action. It presents a great opportunity to exchange good practices and build partnerships around strategies that work, but also to reflect more in depth about the dazzling diversity of practical and theoretical approaches towards meeting the EFA goals by 2015 .

Acknowledgments My special thanks to Simona Popa for her significant contribution to the writing of this editorial. 